\section{Science the only hope?}

SIR-In his commentary, Erwin Chargaff (Nature 327, 199; 1987) voices his objections to certain experiments in the field of human reproduction and to the commercialization of the making of babies. He knows that his objections will have little or no impact, and his moving last paragraph reflects his own state of hopelessness. I recommend all students of the technology of human reproduction to read his article, though I do not share its desperation.

Raised in the same winter of decaying culture in Austria, Chargaff and I have known each other for many decades. We have always agreed to disagree on virtually every aspect of human endeavour, particularly science. I object to his pessismism; he objects to my optimism.

In his article, Chargaff proclaims the end of an era in which science was the never-ending search for truth about nature - a quest that would help us in understanding the workings of our world. With the splitting of the atom and the gene, this era, he says, was displaced by a new one of manipulation and deflection of the forces of nature. Once again I disagree. With all the naiveté I can muster, I believe that science is still the only hope for Homo sapiens.

I am an optimist, as defined by a nuclear physicist, as a person who believes that the future of Homo sapiens is uncertain. I do not believe that political and economic solutions alone will solve our problems. I believe that we have a chance of decent survival only if we can learn about the roots of aggression, hate and greed - if we can learn to raise a new generation that will sublimate the agressions that once upon a time were the forces that led to the evolution of our society, such as it is. I contest Chargaff's pronouncement of a new era of manipulation of natural forces. It is not new, and it will not and should not displace our search for truth. We have always manipulated the forces of nature - we built houses with lightning rods; we eliminated microorganisms that caused epidemics; we killed animals that were enemies or suitable for food consumption; we erected prisons for criminals. Why is it unethical to manipulate a diseased gene? Is it unethical to learn how to repair it just because nature has created it? Is this not another form of creationism, of accepting nature's verdicts without protest?

I am fully aware of the grave ethical questions that we must face, but ethics comes in at the level of execution and not at the level of search. The discovery of the splitting of the atom was not evil, but the use of this knowledge for the destruction of this world is, although if we let it happen, maybe we deserve it.

It is criminal for a childless couple to get a child by killing its natural parents
(Nature 327, 552; 1987), but is it wrong to give a child to a mother by manipulating the fertilization process?

Granted, we do not know, as Chargaff points out, whether such an unnaturally implanted egg or a frozen embryo will breed the same product as its natural sibling. Probably not, and we should tell this to the prospective parents. But how can we tell without trying whether there is a risk? Is it not even possible that an ovum surviving the clumsy hands of the surgeon will be better equipped than its natural equivalent?

Chargaff is distressed by the monetary gains involved in the technology of human reproduction. So am I, but is this relevant to the basic problem? Among the failings of Homo sapiens is greed, a form of aggression that we cannot control. Greed may be unethical or even criminal when it leads to theft or unnecessary surgery; it is a fact of life and not an argument against advances in human reproduction.

I am not a white knight riding on a high horse. I shall not even know whether I am riding a horse or an ass, until, as the Chinese say, the dust settles. I also do not know why we search for truth, and I like to probe into the biological origins of this drive. Yet $\mathrm{I}$ believe that it is among the best gifts nature has given us, a gift that may eventually get us out of the mess Chargaff rightly bemoans.

Efraim Racker

Division of Biological Sciences,

Wing Hall,

Cornell University,

Ithaca,

New York 14853, USA

\section{Vive la différence}

SIR-The apparent innuendo by your reviewer Alan Nunn May (Nature 327, $377 ; 1987)$, that the United States of President Truman needed deterring as much as the Soviet Union of Comrade Stalin, cannot be allowed to pass unchallenged.

If we assume that the United States and the Soviet Union were equivalent in this respect, then it must follow either that the United States and the Soviet Union were equally (un)democratic or that democracy makes no difference.

Both propositions have, I suppose, been advanced by apologists for those whose penetrating intelligence and concern for humanity led them to choose to work for Stalin. I accept neither: the United States is democratic; the Soviet Union is not, and never has been. And democracy does make a difference.

Affander 967 , J.F. CRAWFORD

CH-5305 Wuerenlingen,

Switzerland

\section{Vatican and IVF}

SIR-The Vatican condemnation of in vitro fertilization (Nature 326, 229 \& 268; 1987 ) seems to stem mainly from the elimination of surplus fertilized eggs that this method inevitably entails.

It is of course the right of churches to express ethical views about reproduction as about any other aspect of human life. But to be considered seriously when dealing with a physiological activity, these views should take account of biological constraints. In this context, it has not been stressed that sexual reproduction, in all species, is characterized by an immense destruction of gametes, embryos and juveniles, which may at first sight appear a reckless waste. But all biologists know this is essential for the maintenance of the genetic quality of the species. Even in humans, a slowly reproducing animal with few young, fewer than a score of the 500odd ova produced by the female are ever likely to develop into advanced pregnancy. Taking into account infant and child mortality, the frequency of sterile couples and the death of young mothers linked with delivery, it can be calculated that, in many primitive societies, the average number of children per fertile woman must have neared 8 (in less than 20 years) just to produce the two adults necessary to maintain the population.

In advanced societies, hygiene and modern medicine have progressively reduced the losses of fetuses, infants and children. The equilibrium could only be maintained by the introduction of contraceptive techniques which means the elimination of earlier stages in the reproductive process. Incidentally, the balance is not easy to achieve. Some European peoples now have too few children. On the other hand, when the impact of modern hygiene has been too rapid on psychologically unprepared societies, there is a population explosion.

Anyway, when this destruction of potential human life takes place as early as possible, it leads to a reduction of the total amount of suffering. As long as the Church does not recognize the biological necessity of this elimination, its views can be dismissed. Now, whether fertilization occurs in the "natural" way or is medically assisted, seems morally irrelevant. Is renal dialysis, bypassing the physiological way of making urine, to be damned because it is not "natural"? This does not deny the Church the right to have strong views about other, not strictly biological, aspects of the problem such as surrogate mothers and the choice of sperm donors.

Université de Liège,

Biologie Générale,

Institut de Pathologie Sart-Tilman,

Par B-4000 Liège 1,

Belgium 